\title{
Deepen the Teaching Reform of Operating System, Cultivate the Comprehensive Quality of Students
}

\author{
Jianjun Liu \\ Department of Computer Science and Technology, Dezhou University, Dezhou 253023, China \\ Tel: 86-138 $69280486 \quad$ E-mail: ljj@dzu.edu.cn
}

\begin{abstract}
Operating system is the core course of the specialty of computer science and technology. To understand and master the operating system will directly affect students' further study on other courses. The course of operating system focuses more on theories. Its contents are more abstract and the knowledge system is more complicated. Therefore, combined with teaching practice, the author puts forward some opinions and ideas from two aspects, namely the theoretical teaching and the practical teaching, for the course reform and the development of operating system.
\end{abstract}

Keywords: System simulation, Innovative consciousness, Research-oriented teaching, Autonomous learning

Operating system is the core course of the specialty of computer science and technology. To understand and master the operating system will directly affect students' further study on other courses, and even influence their professional career. This course emphasizes more on theories and the contents are more abstract. Its knowledge system is complicated and virtual. Considering the author's teaching practice, the author advances his views and opinions on the reform and development of operating system.

\section{The status and the characteristics of operating system}

The operating system is the contact platform of computer's software and hardware. It is the core systematic software of computer. It manages computer's software and hardware sources, controls computer's work flow, coordinates users to use computer sources, and improves computer's work efficiency.

The course of operating system is the core subject. Courses of data structure, principles of computer organization, program design language are the preparing courses of operating system. Courses of computer network, compilers: principle and techniques, multi-media technologies are the successive courses of operating system. Therefore, operating system is a connection in the curricula system of computer specialty (Siyang Liu \& Shijian Huang, 2001).

\subsection{High intensive special knowledge and wide and complex contents}

Operating system gains popularity and development along with the development of computer techniques and the application of computers. Its development experiences these stages: manual operation stage, simple batch processing stage, multiple batch processing stage, and time-sharing stage, and network operating system, distributed operating system, and high program design language, data structure, principles of computer organization, and discrete mathematics. In addition, operating system also manages the software and hardware sources in computers and network. These sources are various and complex. Operating system must adapt to these differences in order to manage these sources. Therefore, the contents of operating system are extremely complicated.

\subsection{Knowledge points are difficult and under the influences of environment}

In operating system, some knowledge points, such as process and PV operation, are hard to be understood by students. These knowledge points cover the whole management process of operating system. If students can not understand these concepts deeply, they can not learn the operating system well. Besides, to compile the operating system is a difficult and complex systematic engineer. Students can not understand the principles of operating system completely or know the source codes of a operating system in a short term. Furthermore, for some operating systems, the sources codes are secrets. Therefore, teachers can not analyze the all details of operating system for students.

\subsection{Fast update of contents}

Along with the continuous development of computer techniques and network, the contents of operating system must catch up with the steps of computer techniques. As a practical course, operating system must focus on the combination of theories and practices. Help students to understand the instances of present operating systems. Trace today's latest research fruits. Improve students' sensitive recognition. All these issues increase the difficulties of teaching operating system.

\subsection{Poor operational abilities in practice}

Computer time is a difficult part of operating system. Based on years of teaching experiences, the author explores 
several forms for computer time.

(1) Observation and experience

It is the most initial and simple way for learning operating system. By means of observation and experience, students can understand the connotation of operating system.

(2) Read source code

Select the open and complete source codes and help students to read. It can greatly help students to understand relevant techniques. However, it can not improve students' practice abilities and systematic thinking thoroughly.

(3) Program simulation

Students are required to do a lot for this point. For example, students can actualize the producer- consumer simulation and bankers' algorithm by writing programs. It is similar to programming in practice.

(4) System simulation

It is the most ideal practice mode. Students can practice in real or virtual operating system environment. They can directly operate or modify the core of operating system. By this way, students can master the design strategy and techniques of operating system. However, the system simulation requires a lot for students' operating abilities and experiment environment. It is hard to carry out the system simulation.

All these characteristics turn into barriers for improving the teaching quality in a sense. Only by overcoming sorts of difficulties and barriers, can it actualize the goal of operating system: help students to build sound specialty knowledge system and improve students' system analysis and innovation abilities.

\section{Probe into the teaching reform of operating system}

\subsection{Theoretical teaching}

(1) Emphasize on knowledge system and case study in content

The teaching contents of operating system have two main clues.

The vertical clue means the development of design idea, processing mechanism, and system structure in history. Take the memory management for example. From the early fixed partition to later changeable partition to today's virtual storage management, we can understand the development of operating system thoughts based on time.

The horizontal clue mainly refers to the differences of specific techniques under different environments. Take the process management for example. Linux has five states. Windows have seven states. Some simple operating systems only have three or two states. Different application aims and environments restrict the design and the application of operating system (Jie Ming, 2004).

To adopt the "viewing the history vertically and viewing the world horizontally" teaching thought can help students understand the development of principles and techniques on one hand, which can make students to master the future development trend more exactly. On the other hand, to analyze cases can help students to understand the differences of techniques and the choices of technological tactics, improving students' ability of analyzing practical issues.

(2) Adopt various teaching methods and inspire students' innovative consciousness

Based on characteristics of college teaching, the application of teaching methods should give priority to three points.

Firstly, the research-oriented teaching method. Viewing from the development of modern education, quality education emphasizes on the "rationality" of learning, working, and exploring. Laying stresses on the understanding to the essence of problems can help students to build such a thinking mode: identify the goal --- find the way for achieving the goal --explore the idea or technique for solving the problem. In practice, we should focus on the research-oriented teaching, paying attention to simulating the process of identifying knowledge. Make students to sense the innovative process of knowledge. Improve students' interests in exploring research. Inspire students' consciousness of autonomous learning. And improve students' abilities of innovation.

Secondly, the interactive class communication. Interactive communication between teachers and students in class is a useful teaching attempt. The interactive teaching is a teaching method in which students exert their effects. By this way, it can cultivate students' participation consciousness, practice abilities, and thinking abilities, and inspire students' interests in learning, which is in accordance with quality education that advocates the teaching thought of "take teaching as the dominance and students as the subjects", offering more initiative thinking space for students.

Thirdly, adopt the multi-media teaching method. Along with the development and the combination of multi-media technologies and computer techniques, multi-media enrich the teaching mode by its words, images, and videos. In teaching, multi-media can help to inspire students' interests in computer knowledge by introducing various cases and examples, which can well absorb and maintain students' attentions on class. By this way, students can understand and 
memorize the knowledge. In a pleasure and relax class, students can master the specialty knowledge better.

(3) Analyze the source codes ------ cultivate students' abilities of reading and understanding

Scene teaching is to position students in a special teaching environment, instruct students to study, and inspire students' interests in autonomous learning. Introduce source code analysis in teaching. Take the real application as the direction. Make students understand the teaching contents deeply. For example, the open source code of Linux offers conditions for the teaching of operating system. By analyzing part of source code of Linux, students can read the process management, the memory management, the file management of Linux. Combine the theories with the practice together. Deepen students' understanding to operating system theories. Meanwhile, students can learn the preciseness, the technological thought, and the special style of real system, which can benefit the cultivation of special computer talents (Zongwan Mao \& Li Long, 2002).

\subsection{Experiment teaching}

Experiments of operating system are more observable but less practical. Considering this fact, the experiments should emphasize on the cultivation of experiment abilities. Reform the experiments and design scientific experiments. Step by step, cultivate students' thinking abilities and knowledge- acquiring abilities. By this way, students can possess better learning habits and techniques of experiments.

(1) Help students to understand theories by experiments

Introduce source code analysis in class. Test the program by experiments, such as process, memory management, and file management. Then, students can master and understand the different functions of operating system. In this process, some students with potentials can participate in the preparation for experiments. They can recognize the experiment in general. It can give them a sense of proud. They can guide and help other students and improve the effects of experiments. Meanwhile, in the process of preparing for experiments, students can discuss problems, communicate with teachers, and drive the innovation of education.

(2) Team practice ------ cultivate the experiment ability by interactive teaching

After finishing a chapter, give experiments for program simulation. Before the experiment, teachers should tell students about the key points and main contents. Students can program the system by themselves. At the computer time, students can discuss problems freely. In a fee environment, students can solve all kinds of problems by discussion, which can greatly inspire students' interests in learning and cultivate their team cooperation spirits. By means of experiments, give each student an objective, fair, and exact analysis and evaluation, which can help students form an objective recognition to their studies, actualizing a significant leap (Xi Chen, 2002; He Lin, 2004).

(3) Open comprehensive experiments, perform system simulation, and improve students' practice innovation abilities

After completing the basic functions of operating system, supply a comprehensive subject, such as the design of a simple operating system. Collect materials, retrieve references, design experiments scheme, develop experiments, ask students to write papers, cultivate students' research and practice abilities, and offer chances for innovative practice. As students have already practiced on operating system's partial functions, teachers should direct students to probe into the whole process of operating system, cultivate students' abilities of analyzing and solving problems, inspire students' interests in autonomous learning, and help students to achieve self education, self perfection, and self development, realizing the improvement of knowledge and abilities.

\section{References}

Chen, Xi. (2002). On application of CAI in teaching reform of science. Higher Education of Sicences. No.2.

Lin, He. Liu, Li. Meng, Yingjie. Li, Yongli. Li, Haibo \& Ge, Li. (2004). Some ideas on the teaching of the operating system and on the standardization of experiments. Higher Education of Sciences. No.2.

Liu, Siyang \& Huang, Shijian. (2001). From the operator of experiments to the host of experiments. Teaching Reform Tendency. No.4.

Mao, Zongwan \& Long, Li. (2002). Construct new system of professional experimental chemistry to train innovated talents. Higher Education of Sciences. No.5.

Ming, Jie. (2004). Practice in "participation" teaching and learning in economic and trade courses. Journal of Technology College Education. 